\title{
A DOUBLE-BLIND CROSSOVER TRIAL OF METHANDIENONE (DIANABOL, CIBA) IN MODERATE DOSAGE ON HIGHLY TRAINED EXPERIENCED ATHLETES
}

\author{
D. L. J. FREED ${ }^{1}$ and A. J. BANKS ${ }^{2}$ \\ Departments of ${ }^{1}$ Bacteriology and Virology, and ${ }^{2}$ Orthopaedics, \\ Manchester University, Stopford Building, Manchester
}

Orally-active anabolic steroids have been used since the early 1960's for body-building and athletic purposes; in particular for weight-lifting and other "heavy" events, but also for the "explosive" events such as long-jump and sprint.

Objective evidence of their efficacy and safety is sparse and contradictory, (Fowler et al., 1965, Johnson et al., 1969, O'Shea 1971, Casner et al., 1971, Johnson et al., 1972) and there is a considerable placebo effect, (Ariel and Saville, 1972). Against this background we designed a double-blind crossover trial using methandienone (Dianabol) in doses of $10 \mathrm{mg} /$ day or 25 $\mathrm{mg} /$ day, using only highly-trained male athletes as our subjects. We thus hoped to resolve the controversy in the literature, and find clear answers to the two crucial questions:

a) do anabolic steroids benefit athletic performance?

b) what are their side-effects in this situation?
The trial lasted twelve weeks for each man, steroid and placebo being given in random order for six weeks each. Before the trial began, and at fortnightly intervals throughout it, the following measurements were made: 1) Strength (measured either as percentage improvement over pre-trial performance (Fig. 1) or as percentage improvement over performance at previous visit (Fig. 2))

2) Body weight

3) Skinfold thickness

4) Blood pressure

5) Cholesterol and alanine transaminase (SGPT)

A full account of this work has recently appeared in the British Medical Journal, 1975, Vol. 2, 471-473. May 31st 1975. 'Anabolic Steroids in Athletics: Cross-over Double-Blind Trial on Weightlifters' by D. L. J. Freed, A. J. Banks, D. Longson, and D. M. Burley.

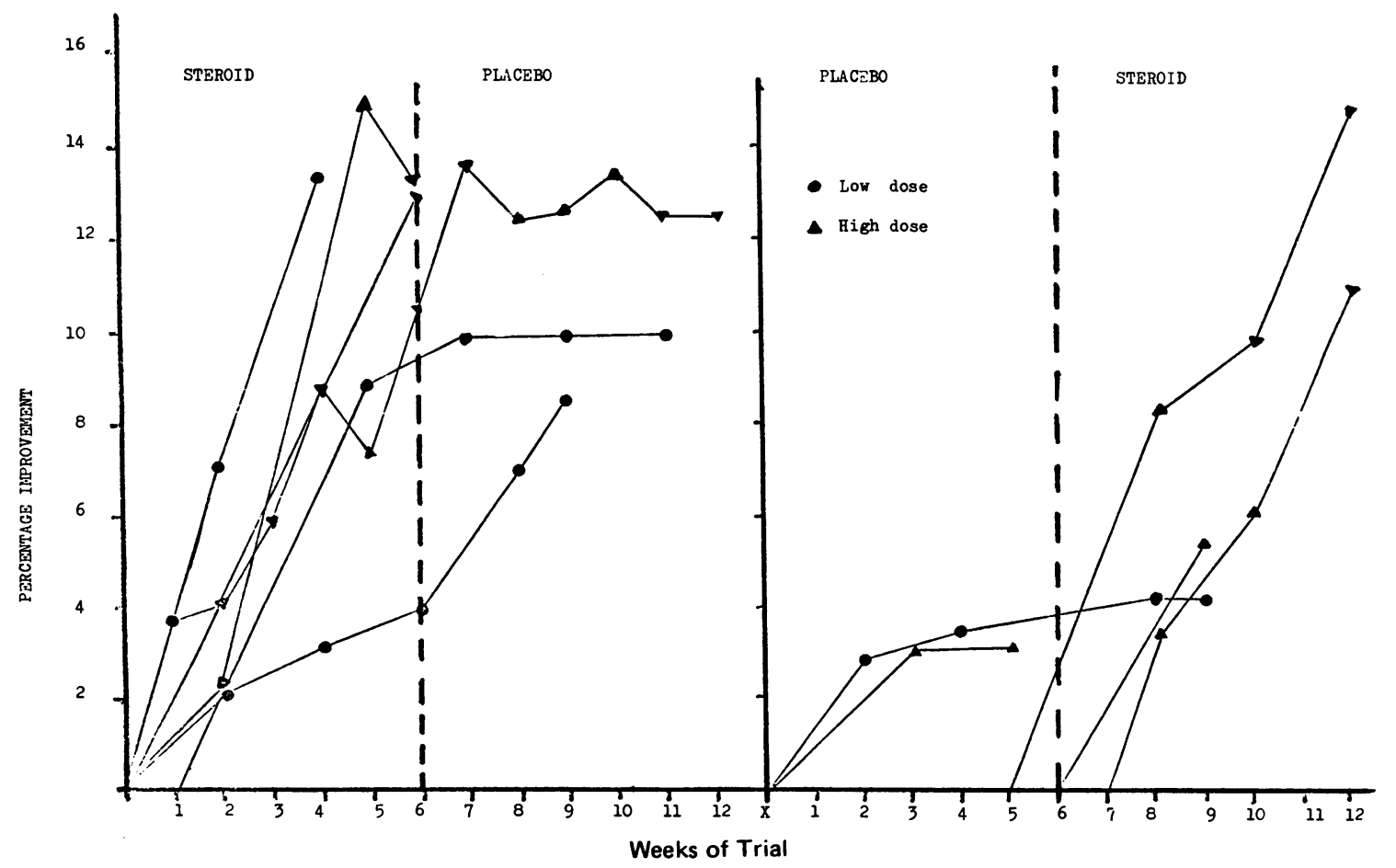

Fig. 1. Average athletic performance expressed as a percentage of pre-trial performance 


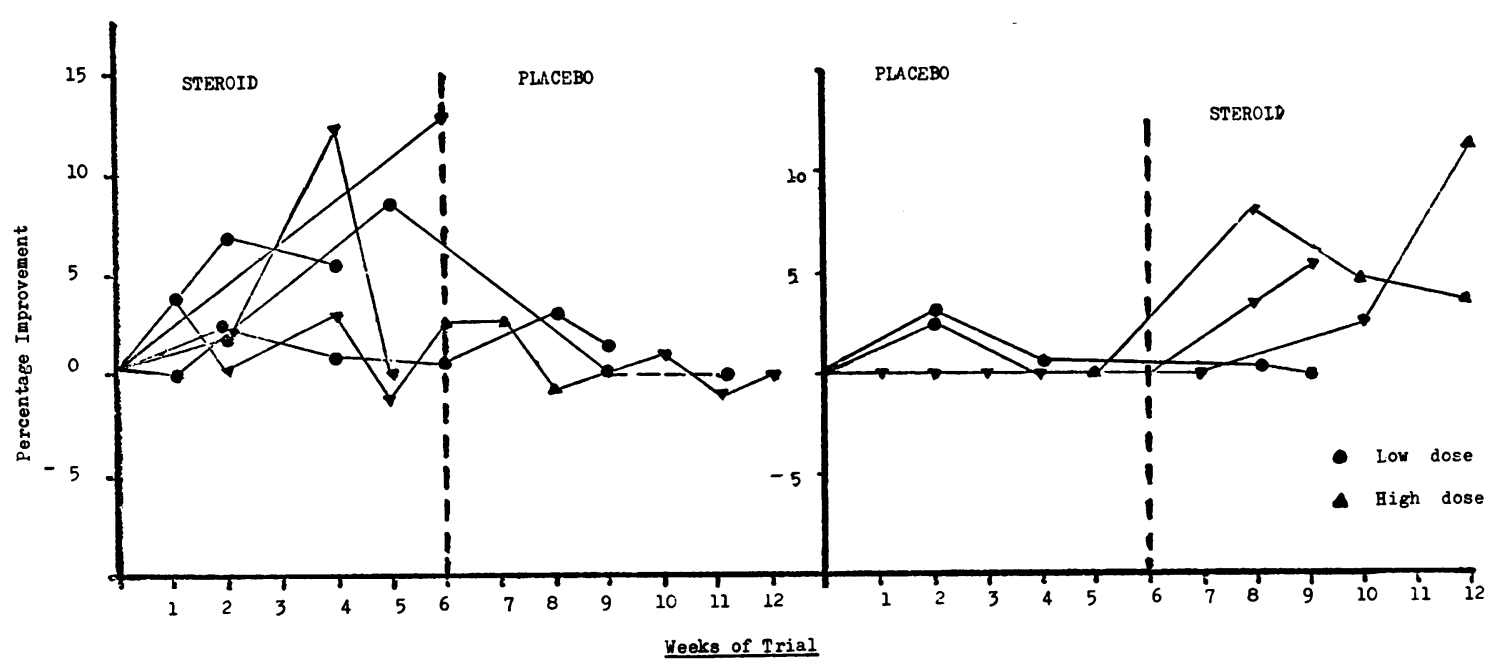

Fig. 2. Average athletic performance expressed as a percentage of performance reported on previous visit. Any point greater than zero means that improvement has occurred since then.

General health was assessed by clinical interview and examination and any side-effects were noted. The subjects pursued their regular training routine throughout. As each man approached the end of the trial and before the code was broken, he was challenged to predict the sequence of placebo and steroid in his case.

\section{Results}

Thirteen men took part, of whom only five furnished complete records for analysis. The remainder either defaulted from their placebo period or withdrew during the steroid period because of side-effects.

In spite of this incompleteness, it is possible to calculate an average percentage improvement for both placebo and steroid, using the data in Figure 2. There are eight sets of "placebo" results and ten sets of "steroid" results. The former show improvements of 0 - $2.3 \%$ and the latter show improvements of 0.3 $13.0 \%$. The difference is significant at the $1 \%$ level. After stopping the steroid, the three men who continued into their placebo period showed maintained or even continued improvement.

Body weight rose significantly while on methandienone $(p<0.001)$. In contradistinction to strength, the weight fell rapidly back to pre-trial levels on stopping the steroid. No change in skinfold thickness was seen at any time, so it would seem that the increase in weight is more likely due to water retention than to increased muscle bulk.

Blood pressure rose slightly while on methandienone (Fig. 3). The rise is significant for the systolic pressures at the $5 \%$ level, but not the diastolic.

Cholesterol levels showed a slight tendency to rise throughout the trial period, irrespective of which order the tablets were given. This is perhaps explicable when we remember that meat and milk form a large part of athletes' diets, and no attempt was made to control recent food intake when the blood samples were taken.

\section{TABLE I}

\section{Showing side-effects occurring during Methandienone therapy in 13 subjects}

\section{SIDE EFFECTS}

Acne

Headache/dizziness

Reduced sexuality

Urinary trouble

Hypertension

Raised SGPT

Withdrew Due to side-effects

Total Subjects experiencing side-effects

The SGPT level remained as a rule within normal limits, but in two cases was seen to rise; once to 35 units/ml. (treatment was continued and the SGPT returned to normal) and once to 75 units $/ \mathrm{ml}$ (treatment was stopped, and the level returned to normal).

Other side-effects (Table) included acne, headache, 


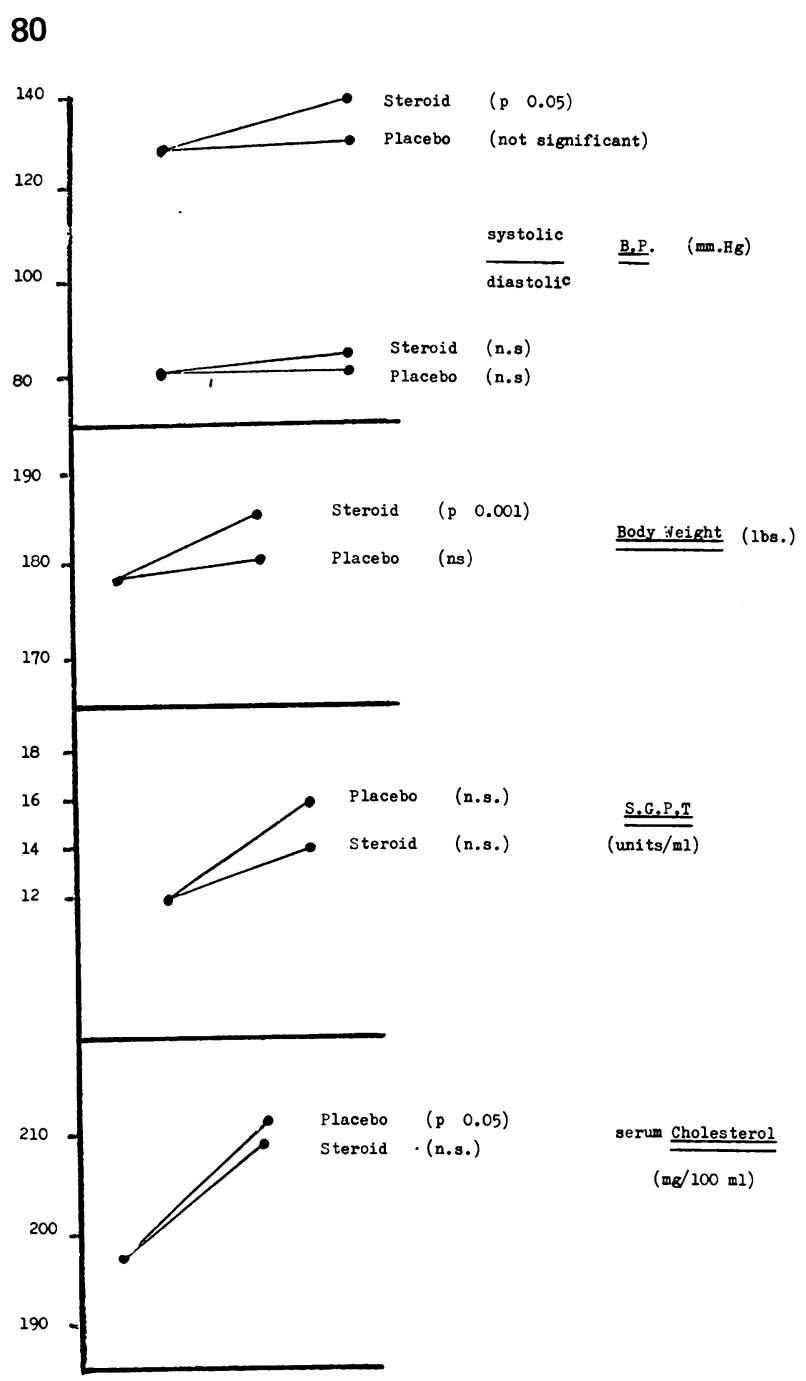

Fig. 3. Change in Blood Pressure, Body Weight, S.G.P.T. and serum Cholesterol values during steroid and placebo therapy. n.s. = not significant

dizziness and nausea, and one case of greatly raised blood pressure $(150 / 110)$ associated with fainting during lifting. This last occurred in a man who had shown a gradual tendency to rising blood pressure while on methandienone (from 125/85 to 130/105), and after this episode he withdrew from the trial.

All side-effects disappeared within two weeks of stopping the methandienone; none was seen during placebo treatment.

All thirteen correctly discerned which tablets contained steroid and which placebo. None of the effects of methandienone seen in this trial was dosedependent.

\section{Discussion}

The two initial questions can thus be answered. Anabolic steroids do aid athletic performance, at least under the conditions of dosage, timing, exercise, diet and previous experience that we insisted on. Their use is associated with side-effects, though none that we saw was permanent.

In addition we can say that the drug does encourage weight gain, but we do not think this due to increased muscle mass. The same conclusion was independently drawn by Casner et al., (1971) on the basis of their specific gravity studies.

This trial therefore joins with those of O'Shea (1971) and of Johnson et al., (1972), in confirming the athletic efficacy of anabolic steroids. All three studies were made on previously-trained athletes, whereas the studies of Fowler et al., (1965) and Casner et al., (1971) employing healthy young men of mixed athletic habits, showed no such effect. It may be therefore that anabolic steroids do not exert their effect on muscles which are not simultaneously exercised (a point which could perhaps improve their reputation in the spheres for which they were originally marketed - debility and convalescence). Indeed, it has been our experience that if a particular muscle-group escapes exercise during training, it fails to show the improvement that the other muscles display.

We found a much greater incidence of side-effects than has been reported in previous published trials. Numbers are so small that chance may be the culprit for this, but our general anecdotal knowledge of this field leads us to believe that side-effects are fairly common.

We have heard of doses of up to $300 \mathrm{mg} /$ day being taken by athletes, but there is no evidence, objective or anecdotal, that these huge doses achieve any greater effect than the doses used by us. On the other hand, we have heard of cases of jaundice, prostatism, hypertension, gastro-intestinal haemorrhage, increases and decreases of libido, oligospermia and aggressiveness associated with steroid usage, though once again there is no evidence of dose-dependence. Indeed, some men are known to have taken large doses for at least two years without ill-effect.

Most men taking anabolic steroids claim that there is a lower incidence of training-injuries, and that when these do occur they heal more quickly. There is said to be a general decrease in fatigueability, allowing longer, more strenuous and more frequent training sessions. 


\section{Ethical Considerations}

We do not believe that the acquisition of knowledge in itself justifies the performance of an immoral procedure, and we are aware that the taking of anabolic steroids for athletic reasons can be criticized on at least two ethical grounds:

1) they give the competitor an unfair advantage over opponents not taking them;

2) it is wrong to give a drug to a healthy person. follows:

In this particular case, we met these objections as

1) since the usage of these drugs is reputed to be almost universal among athletes at international level, not to take them is to submit to an unfair disadvantage;

2) all of the subjects for our trial had already determined to obtain the drugs, legally or otherwise, and take them. In these circumstances, it would be better if they obtained the drugs legally, and took them under medical supervision.

As regards the uncontrolled use of anabolic steroids in the field, however, we feel that the ethical objections stand. In addition, the practice encourages a lively black market, and, worst of all to a doctor, exposes these young people (who should be the very epitome of health) to potentially hazardous agents which may harm their health in the long term.

We would support any steps by the sports authorities to prevent their use, provided that these steps were effective. In the present state of knowledge, however, we doubt if an effective ban is feasible.

\section{Acknowledgements}

The authors acknowledge with gratitude the help of: Dr. D. Longson, Consultant Physician, Manchester Royal Infirmary, for assuming overall clinical responsibility for the trial.

Dr. D. Burley, Head of Medical Services Division, CIBA Laboratories, for kindly providing us with drugs and placebos, and for advising us on the design of the trial. Mrs. S. Standen, Statistitian, CIBA Laboratories, for the statistical analyses.

Mr. R. St. G. T. Harper and Mr. R. Walker, for allowing us the use of facilities at the McDougall Sports Centre, University of Manchester.

\section{REFERENCES}

Ariel, G. and Saville, W., (1972) "Anabolic Steroids: The Physiological Effects of Placebos". Medicine and Science in Sports, 4: 124-126.

Casner, S. W., Early, R. G. and Carlson, B. R., (1971) "Anabolic Steroid Effects on Body Composition in Normal Young Men" Journal of Sports Medicine and Physical Fitness, 11: 98-103.

Fowler, W. M., Gardner, G. W., Egstrom, G. H., (1965) “Effect of an Anabolic Steroid on Physical Performance of Young Men" Journal of Applied Physiology, 20: 1038-1040.

Johnson, L. C., Fisher, G., Silvester, L. J., and Hofheins, C. C. (1972) "Anabolic Steroid: Effects on Strength, Body weight, Oxygen Uptake and spermatogensis upon Mature Males" Medicine and Science in Sports, 4: 43-45.

Johnson, L. C., and O'Shea, J. P., (1969) “Anabolic Steroid: Effects on Strength Development" Science, 164: 957-959.

O'Shea, J. P., (1971) "The Effects of an Anabolic Steroid on Dynamic Strength Levels of Weightlifters" Nutrition Report, International, 4: 363-370. 